\title{
The BGR contingency model for leading change
}

\section{Derek R. Brown*, Raymond Gordon and Dennis Michael Rose}

School of Management and Marketing,

University of Southern Queensland,

Springfield Campus,

Queensland 4300, Australia

Email: stewartb50@msn.com

Email: ray.gordon@usq.edu.au

Email: dennis.rose@usq.edu.au

*Corresponding author

\begin{abstract}
The continuing failure rates of change initiatives, combined with an increasingly complex business environment, have created significant challenges for the practice of change management. High failure rates suggest that existing change models are not working, or are being incorrectly used. A different mindset to change is required. The BGR Contingency Model (named after the authors' surnames) for leading change facilitates the required mindset, and addresses the issue of leadership decision-making as one of the major contributors to high change initiative failure rates. Drawing on four propositions offered, the conceptual model is based on the interdependency of ethics and logic in leadership decision-making in change initiatives. The model has specific, formal checkpoints of this interdependency. Its basic design is a series of progressions, or groups of tasks, which start with the strategic and continue through the operational to the tactical levels of the organisation, in an iterative fashion.
\end{abstract}

Keywords: change management; leadership; ethics; decision-making.

Reference to this paper should be made as follows: Brown, D.R., Gordon, R. and Rose, D.M. (XXXX) 'The BGR contingency model for leading change', Int. J. Learning and Change, Vol. X, No. Y, pp. $\mathrm{xxx}-\mathrm{xxx}$.

Biographical notes: Derek R. Brown has over 30 years' experience in designing and managing large and complex change initiatives in a variety of industries and countries. He has built and led successful change management practices in Big 4, mid-tier and small, specialist consulting firms.

Raymond Gordon is a Lecturer in the School of Management and Marketing at the University of Southern Queensland Springfield. He earned his $\mathrm{PhD}$ in leadership from the Queensland University of Technology. He has had more than 20 years of management experience in small, medium and large businesses. He was a former executive at SUNCORP, where as a line manger he was directly responsible for leading the change from functional divisions into one business unit. He was CEO of a business consultancy for eight years, and was registered as a Psychologist in Queensland specialising in Industrial and Organisational Psychology. 
Dennis Michael Rose is a Lecturer at the School of Management and Marketing in the University of Southern Queensland, Springfield. He earned his $\mathrm{PhD}$ in Human Resource Management from the Queensland University of Technology. He is a member of the Academy of Management, the Australian and New Zealand Academy of Management, is a registered psychologist and has consulted in strategic planning and organisational climate. His main research themes are responsible leadership, organisational change, strategic human resource management and organisational behaviour.

\section{Introduction}

The continuing failure rates of change initiatives may indicate a potential deficiency in existing change models and their application. The purpose of this paper is to present a new contingency model of change which seeks to address some of the people-related issues that have been cited as major contributors to the continuing failure rates. The discussion will be illustrated by strengthening the leadership decision-making process through the inclusion of ethics/logic decision points and conceptualising and managing the change process as a series of progressions rather than linear change phases; change managers are more likely to avoid past mistakes identified in change failures. While previous research has made major contributions in the understanding of linear models of change such as discontinuous/continuous and radical change, very little research has examined the differentiating factors of ethics and logic in models of change. First, the BGR model requires formal checks of both ethical and logical elements of leadership decision-making. Second, the model requires the proactive use of organisational learning before a project is approved. Third, the model addresses the historical contributors to failure rates including people issues before the project is approved. The potential contribution of the BGR model includes a stronger focus on: (a) fewer projects approved to begin as originally proposed and (b) lowered expectations on project success such as stakeholder engagement, leadership support and political interference.

First, the paper provides a definition of the key philosophical terms of logic and ethics and then explains the general background to the perceived problem. Next, we present the research of change initiative failure rates and highlight the continuing pattern of people-related issues as major contributors to those statistics. Focusing on the specific issue of leadership in change initiatives, the discussion presents an argument that logic/rational-based decisions such as traditional quantifiable business cases omit or ignore the ethical component. We present a number of examples which highlight the outcomes when the ethical component is absent. Finally, a number of propositions of the conceptual model are developed as questions to be explored in subsequent research.

\section{Background}

For the purposes of this paper, ethics is defined as the standards by which we should act (Velasquez et al., 2009; Patzer and Voegtlin, 2010). Logic is what directs and orders our thinking processes; to do what is right (Smith, 2011). Research illustrates a consistently high-failure rate of change with leadership as one of the major and most consistent 


\section{The BGR contingency model for leading change}

contributors (OASIG, 1995; The Standish Group, 1995; KPMG, 1997; A Guide to ERP Success, 2001; Cooke et al., 2001; Eser et al., 2007; Keller and Aiken, 2008; Patzer and Voegtlin, 2010; Qassim, 2010; Petouhoff et al., 2011). According to Burnes (1996), change initiatives have been increasing in speed and size since the 1990s and have led to many business failures. Recent scandals in the business world have resulted in significant concern with, and loss of confidence in, business leaders (Coldwell, 2010; Schwab et al., 2010). However, public outcry about a number of scandals has done little to halt the number of increasing change initiatives (Dassah, 2010; Patzer and Voegtlin, 2010; Petouhoff et al., 2011). The aggregated impacts of consistent project failure rates, increasing volume, pace and complexity of change initiatives, and leadership concerns create a complex situation involving leadership, decision-making, change management and leadership ethics. Consistently high patterns of failure rates have been compounded by social and political pressures and public scrutiny. Leadership is at the centre of this activity.

The evolution of scholarly approaches to change has produced many empirical models, methodologies and approaches. The ontology of knowledge is now regarded as a credible, valuable and much needed discipline. The pervasive rates of failure in change initiatives, however, suggest that existing models, methodologies and approaches can be challenged. Significantly, practitioners increasingly struggle with change model applications. Similarly, organisations are not learning from their own or others' experiences. In this context, a different mindset to change supported by a different change conception is required. This paper proposes that the BGR contingency model for leading change is a useful approach for subsequent empirical research.

\section{Research on change initiative failures}

A great deal of research has examined change project failure rates (OASIG, 1995; The Standish Group, 1995; KPMG, 1997; A Guide to ERP Success, 2001; Cooke et al., 2001; Eser et al., 2007; Keller and Aiken, 2008; Patzer and Voegtlin, 2010; Qassim, 2010; Petouhoff et al., 2011). The basis of these studies is that project failure rates have been consistently, almost predictably, high. The studies show that failure rates are generally consistent across all industries. Similarly, change failures have been consistently reflected in organisational strategy, technology, process and operational projects. Most significantly 'people-related' issues are the most consistently highest rated failure factors including leadership and leadership-related factors.

The social and political focus on the current state of business and business organisations is intensifying and raises the issue of the ethics of leaders. One outcome has been a 'back to basics' revisit of the purpose of business generally. Philosophically, the exclusive purpose of business is to make profit. However, profit goals without moral guidance have been questioned (Green, 2009). The global financial crisis has highlighted the influence of greed and selfishness within corporations and the quality of leadership (Bakan, 2004; Fulmer, 2005; Richoltz, 2009; Benson and Soldo, 2010; Patzer and Voegtlin, 2010). Societal and political demands of business are increasing against a backdrop of increasingly sophisticated consumer needs (Dassah, 2010). One consequence of this microscopic scrutiny of business leaders has been an intense focus on leadership ethics. 


\section{Case 1}

The continuing economic, social and political costs of poor change implementation are increasing and a different mindset is required about the approaches and models of change. Organisations have not learned from the history of change initiatives. Decisions based on a logical/rational basis alone have potentially significant negative consequences. An example of both of these is the recent implementation of a new payroll system by the Queensland Health organisation in Australia. During the 1980s and 1990s, the Queensland Government had a very large number of systems implementation projects approved. These projects were contracted to consultants as systems integrators responsible primarily for project management. Projects ranged from tens of millions to hundreds of millions of dollars. Departments began to be questioned about these expenditures and pressure was applied to manage projects internally to save consultancy fees and increase accountability.

Against all available advice, historical evidence and guidance, leadership in the Queensland Health Department elected to manage one project (Work-Brain/SAP Payroll Implementation) internally. The decision to manage the project internally placed a significant financial, social and organisational burden on employees. Moreover, there was significant negative budget impact on the organisation resulting in decreased leadership credibility and political implications. The original project was eventually abandoned resulting in lost revenues and the new project had to be rescheduled and re-budgeted with an estimated additional cost in the tens of millions of dollars (AAP, 2010). As a result of poor change of the payroll system, employees are still impacted by disrupted wage and salary payments, confusion over amounts owed and paid, as well as recent threats of legal action and accusations of fraud (Caldwell, 2010; Miles and Wardill, 2010). The review of the situation by the Queensland Auditor General's Department found that leadership decisions were taken to continue with the project in spite of very significant signs and warnings of risks which went unheeded (AAP, 2010). Irrespective of exactly why these decisions were made, the organisational environment and decision-making processes allowed the initiative to go forward in spite of the evidence. This case is an example of decision-making where the history of change initiatives was dismissed or ignored. It also highlights how the ethical elements of leadership in decision-making were absent. Inclusion of an ethical element in the decision-making process would have resulted in a clear understanding of a 'worst-case' scenario. The ongoing consequences of staff not being paid, public exposure and the need for increased contingency budgeting would have been considered in a more ethical approach to change.

Case study 1 suggests that critical decision-making points were ignored such that effective adjustments could be made and collateral damage minimised. Persisting in high-risk change decisions without regard to the impacts on staff was unethical. The BGR model is specifically designed to more effectively facilitate critical decisions about change initiatives by forcing early analysis of the interdependency of ethics and logic in the decision-making process. The increased scrutiny of our business leaders has resulted in an increasing interest in leadership ethics as a major practical and theoretical issue (A Guide to ERP Success, 2001; Ferris et al., 2002; Sims, 2003; Koestenbaum et al., 2004; Brown and Trevino, 2005; Ciulla, 2006; Buchanan, 2008; Green 2009; Neubert et al., 2009; Rosenthal 2009; Lynham et al., 2010). According to these researchers, ethics is core to the concept of leadership. Rosenthal (2009) contends that because leadership is 


\section{The BGR contingency model for leading change}

by its very nature compromise-ridden, ethics is more than a luxury; it is central to how one defines leadership. Combining Rosenthal's contention with the assertion that leaders must be both ethical and effective and that moral failure must be prevented, this leads to the first proposition (Ciulla, 2006).

Proposition 1: Successful change must intentionally and overtly address the issue of the interdependency of ethics and logic in leadership decision-making.

Case 2

Managers are familiar with situations where doing what seems right and doing what is right are not aligned. For instance, the business case that calls for significant cost reductions at the expense of jobs in the workforce that particularly affect low income and one wage families. The logical decision is clear (reducing costs) but creates an ethical challenge (the affect on families). Green (2009) cites the case of HSBC bank and its initiative to provide sub-prime mortgages to allow poorer people to purchase homes. $\mathrm{He}$ concludes that in this example, truth associated with logic (i.e. the organisation will make a large profit), is not equated with good ethics (i.e. the provision of homes to poorer people who cannot make the payments). In this scenario, people securing mortgages were unemployed meaning that logic and ethics were not aligned resulting in a crisis.

Case 3

A more recent example is the controversy over the insurance industry handling of the 2010/2011 Queensland flood disaster. Many publicised horror stories tend to have a common theme; people bought insurance in good faith, believing they were covered for natural flood disasters. Subsequently, people later realised they were not insured for this kind of disaster. This led to increased controversy about the reactions and responses of the insurance companies. From failure to attend well-publicised meetings in Ipswich to insensitive and inappropriate internal emails (Robertson and Solomons, 2011), the behaviour exhibited by insurance firms created a perception of poor social commitment and a lack of integrity. An interesting postscript has been the response of insurance companies to include flood cover in insurance policies. However, customers renewing their policies in 2012 have been shocked to find that their premiums have risen by up to, and sometimes exceeding, $1000 \%$. There were many causal factors and response issues surrounding this series of events bringing into question the relationship in these companies between change and leadership. Coldwell (2010) makes an observation that although business is fundamentally about profit, business cannot continue to operate as it has done in the past as illustrated by the increasing number of scandals and ethical issues that continue to surface at times when business needs to demonstrate leadership. He argues that to revolutionise its operating models, business has to put the public good before profits. Public good he suggests is not exclusively about profit creating jobs. Rather, it includes social, economic, environmental and other elements (Coldwell, 2010).

Change management researchers have identified themes of content, contextual and process issues, which help identify an appropriate change approach to a specific context (Armenakis and Bedeian, 1999; Burke, 2002). Armenakis and Bedeian (1999) define content issues as the targets of change programmes including organisation structures, incentive systems and strategy. Contextual issues incorporate the external and internal forces or conditions that dictate change success and become the drivers of change initiatives. External conditions include those issues outside of the control of the organisation such as 
government regulations. Internal conditions such as work and task concerns are in the control of the organisation. The process classification comprises those detailed tasks and actions taken by the organisation during the change process. The significant aspect of the process classification is that it includes external, organisational and individual elements. However, there is no single best approach to change as the drivers, scope, political environment, and other change driving elements of each situation are different and unique. This means that nearly all change initiatives require a contingency approach (Dunphy and Stace, 1993), which leads to the second proposition.

Proposition 2: The complexity, pace and volume of change demands a contingency-based approach to managing change.

The need to link culture and change is consistent with the work of Armenakis and Bedeian (1999). These and other scholars suggest that cultural analysis is necessary to determine change readiness. Resistance factors can be more readily identified. Aligning current culture with the vision for change including change readiness can increase broad initial support for change initiatives. Change initiatives that are sensitive to culture allow for the design of effective interventions. Cultural norms can directly impact the success of change initiatives. For instance, Schein asserts that the deepest levels of culture are cognitive: “... thought processes that the group comes to share will be the ultimate causal determinant of feelings, attitudes, espoused values, and overt behaviour". Similarly, the effects of change initiatives will either reinforce or alter existing cultural tenets. Cultural issues not directly addressed during a change initiative can impact the effects of the change (Latta, 2006) suggesting that a thorough analysis of cultural determinants is required before change initiatives are attempted. Latta's argument leads to the third proposition.

Proposition 3: The criticality of culture in successful change programmes requires that cultural issues be identified and addressed as early as possible in the development of a change initiative.

Generally, change activities have been grouped as phases or stages which by definition have a beginning and an end. We suggest that this positioning is misleading. Since most change initiatives are part of a larger project, the tendency is to fit them into a project framework, i.e. tasks, estimates, schedules, estimates to complete and so on. In that environment, a phase or segment takes on a specific meaning and creates expectations of time to complete and other outcomes that are generally unrealistic. This leads to the fourth proposition.

Proposition 4: Change activities are most impactful as iterative progressions that continue throughout a project.

It is possible to use these propositions and observations to extrapolate a number of common characteristics that an effective change model should include. These are: (a) an underlying philosophy or theory of change, (b) a contingency-based approach, (c) proactive and intentional strategies for incorporating ethical and logical elements into leadership decision-making, (d) a focus on tools and processes for achieving individual ownership and behavioural change, (e) flexibility to allow continuous update and input from other disciplines and (f) intentional and proactive management of cultural issues. On the basis of this discussion, it is now possible to discuss the BGR contingency model of change. 
The BGR contingency model for leading change

\section{The BGR contingency model}

The BGR model of change is based on a number of design drivers. These include greater flexibility to allow use of preferred tools and methodologies, an adaptability to both organic and transactional change initiatives, clearly defined checks of the ethics and logic dynamic with forced decision points, iterative and flexible work segments, clear and continuous leadership accountability and defined guidelines and strategies for addressing people-related issues. Using these design drivers, the authors have developed the conceptual model illustrated in Figure 1.

Figure 1 The BGR model for leading change (see online version for colours)

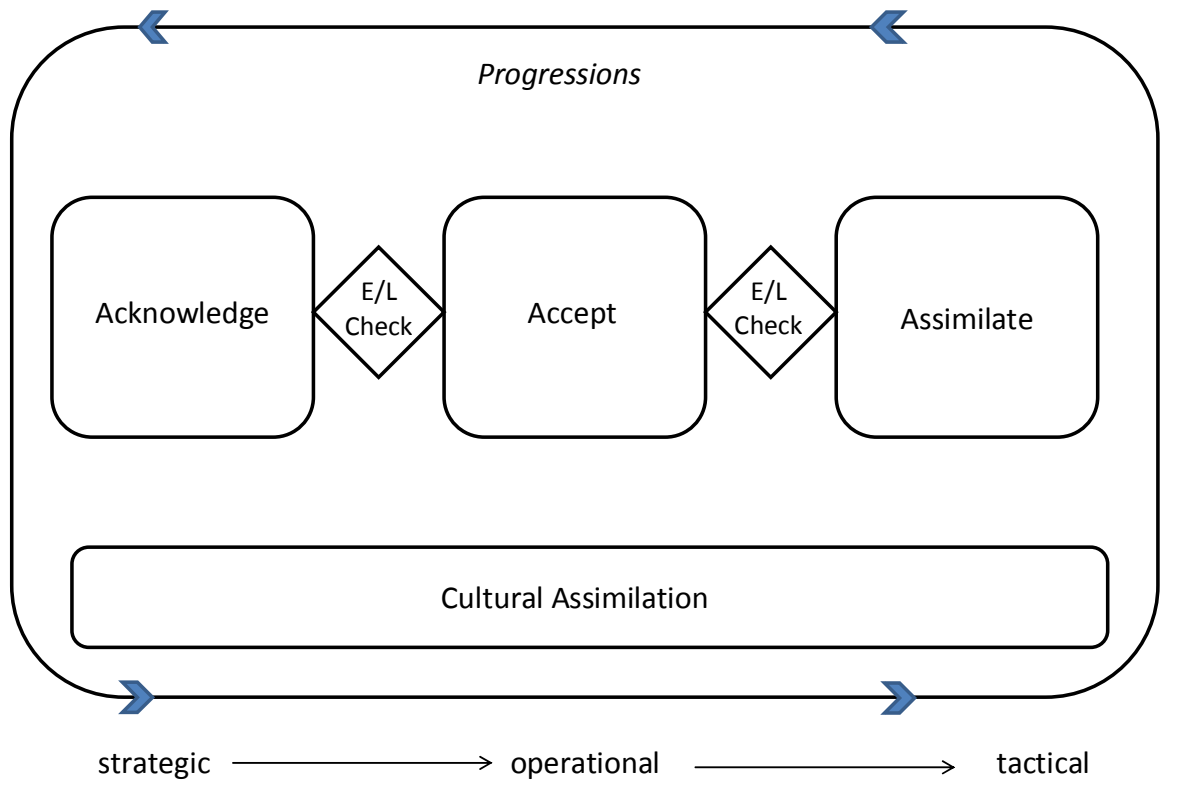

The first characteristic of the BGR model is that all activities are progressions. This means that no single group of activities in a change initiative ever completely ends. More importantly, it is imperative that change activities in general are not forced into project management schedules designed for more definable tasks such as systems integration. The second characteristic of the model incorporates cultural assimilation from strategic through to operational and tactical domains. It has been suggested that successful change can only be claimed when changes become part of the culture (Kotter and Cohen, 2002; Phelan, 2005; Latta, 2006). Cultural assimilation must permeate the change process from concept through to completion and progress from the strategic through the operational to the tactical levels of the organisation.

The third characteristic of the model is that it commences with the strategic-level decision-making processes of an acknowledge progression and the first ethics/logic checkpoint highlighted in Figure 2. Of itself, the acknowledge progression characteristic provides valuable historical, advisory and other information and input into the decision 
process. As an integral part of the overall model, this characteristic is critical for providing the first 'Stop/Go' decision point of the change initiative. Using the Queensland Health Payroll System example, the E/L Checkpoint would have forced a review and analysis of the history and advice previously compiled, documented the analysis process and criteria, confirmed and publicised the consequences of all alternatives and recommendations, and provided justification for the decision to stop the project or continue with it. This would have been done not in the traditional context of risk management, but by thoroughly identifying both the logical (financial and business) and the ethical (social and political) decision criteria. If the business case (logic) is substantiated, but the social (ethical) consequences are unacceptable, then the 'Stop' decision is made.

Figure 2 The BGR model for leading change - acknowledge progression (see online version for colours)

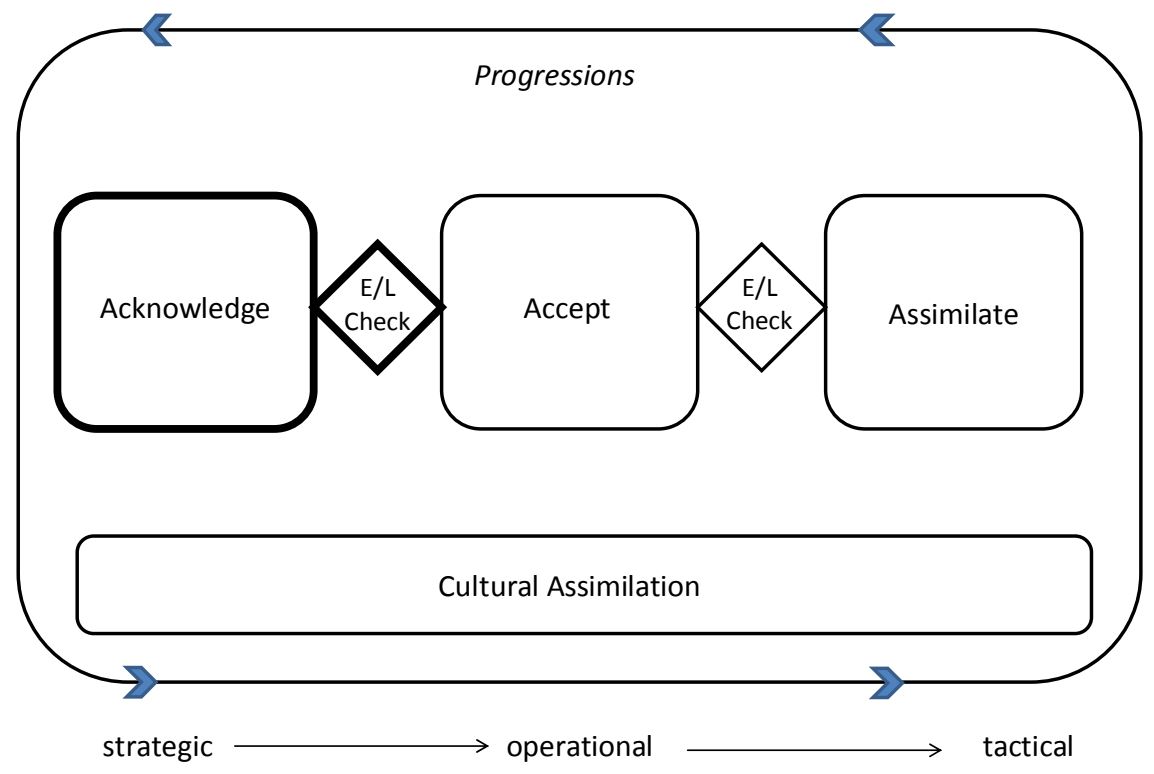

If the ethics/logic test is positive, then the initiative continues to the accept progression, with the clear assumption that the acknowledge progression will continue (see Figure 3 ).

The accept progression builds on the information in, and commitments of, the acknowledge activities. The business and social/political needs and outcomes are clearly described and communicated, and organisational commitment is required. Once again, the $E / L$ checkpoint is mandatory here. Thus far, the model has two critical differentiators. The first is that the acknowledge and the accept progressions are focused on the strategic level and issues with the accept providing a bridge to the operational and tactical levels. The impact of this is that many of the political and organisational issues are at least raised and defined and the major areas of leadership alignment and resistance identified and addressed. Leaders are aware of the organisational intent and attitude to the initiative, and expectations are more definitively and clearly communicated. The intent is to create an initial mindset about the initiative that frames the remainder of the process. 
The BGR contingency model for leading change

Figure 3 The BGR model for leading change - accept progression (see online version for colours)

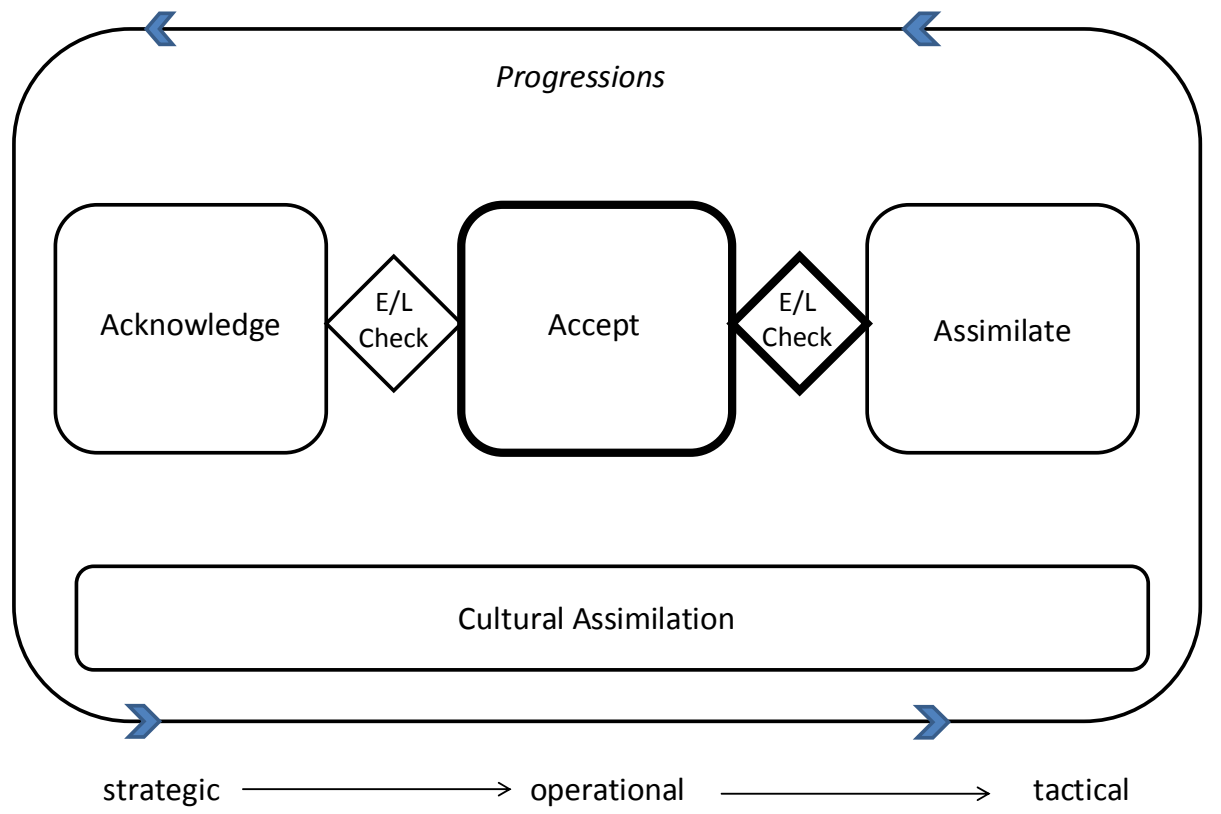

The second differentiator is the impact of the E/L checkpoints on the role and accountability of leadership. There has always been consideration of the need for leadership alignment and buy-in as well as continued support in change initiatives. Unfortunately, this has always proven difficult to achieve and maintain to the level required. Accountability has been easily abrogated and sponsorship diluted. The intent of the strategic focus of acknowledge and accept progressions, and the strict enforcement of E/L checkpoints as 'Stop/Go' decision points is to clearly assign leadership accountability and to identify the owners of the initiative.

At this stage, it is worth reviewing the impact of the cultural assimilation element of the model. In the acknowledge stage we challenge leadership and organisational values, attitudes and behaviours, i.e. culture. At a strategic level, organisational attitudes to customer impacts, social responsibility, transparency and strategic business intent would have been raised. At an operational level in the accept progression, functional and departmental leadership commitment is addressed. Terminology common to decisionmaking such as passive resistance, covert resistance, mental try-out are addressed. Along with the previous progression stage, the initiative does not continue without a successful E/L checkpoint.

The fourth characteristic of the model is assimilation progression. This stage concerns the series of activities associated with operationalising the required changes. This progression involves traditional activities such as communications, stakeholder management and impact assessments. Clearly, if an alternative approach is selected here, E/L checkpoints must continue if the benefits of our model are to be realised (Figure 4) 
Figure 4 The BGR model for leading change - assimilate progression (see online version for colours)

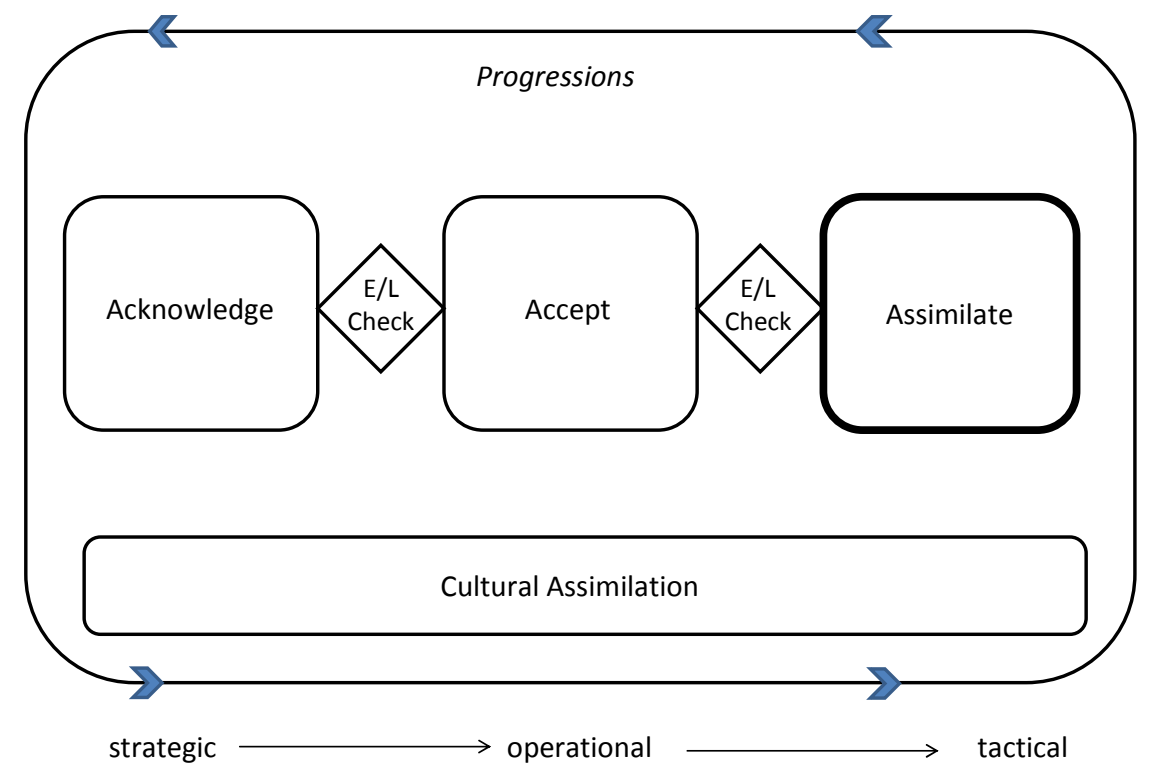

The intentional outcomes of the BGR model are formal and significant decision-making tests and challenges and an intentionality element. The organisational learning opportunities exist since they force decision-makers to address issues that might have otherwise been buried or obscured. The stages of the model address the can do (logic) and the should do (ethics) of change. While leadership buy-in and support requirements are present in a number of existing methodologies, these requirements must be raised before the initiative begins and continues through each stage of decision-making and change implementation. Stakeholder engagement and management must also begin much earlier and be more directive. The BGR change model achieves these requirements for change by inclusion of the acknowledge and accept progressions, and the continuous and progressive ethics/logic checkpoints.

\section{Summary}

The purpose of this paper was to present a new contingency model for leading change initiatives. The continuing high rates of change failure, the increasing complexity of the business environment and the intense scrutiny of business leadership suggest that successful change depends more on people-related issues particularly leadership. The paper developed four propositions that addressed the characteristics of the model. These propositions restated included: (a) successful change must intentionally address the issue of the interdependency of ethics and logic in leadership decision-making; (b) the complexity, pace and volume of change demands a contingency-based approach; (c) the criticality of culture in successful change programmes requires that cultural issues be identified and addressed as early as possible in the development of a change initiative; and (d) change activities are most impactful as iterative progressions that continue throughout a project. 


\section{The BGR contingency model for leading change}

The paper highlighted several cases where the ethical component was lacking in previous change attempts. Based on research and examples from industry, it was possible to propose four design characteristics for a new conceptual model for leading change. The BGR contingency model for leading change is based on intentionally addressing the interdependence of ethics and logic/rationality in leadership decision-making in change initiatives. The authors believe the significance of this work lies in the differentiating factors of the proposed conceptual model. First, the BGR model requires formal checks of the consideration of both ethical and logical elements of leadership decision-making. Second, the BGR model requires the intentional and proactive use of organisational learning before a project is approved. Third, the BGR model addresses the historical contributors and antecedents to past failure, the people issues and other contexts before the project is approved. The outcomes of applying the BGR model could potentially include: (a) fewer projects actually approved to begin as originally proposed and (b) lowered impact on projects of 'softer' issues such as expectations management, stakeholder engagement, leadership support and politics.

\subsection{Implications for practice}

The BGR model repositions change leadership. Application of the E/L checkpoints in the first two progressions has two critical implications for change practitioners. First, change is strategically positioned in a proactive, project-defining role. Change practitioners have an opportunity to define the initiative as a change project integrating systems, process and other activities, as opposed to the more traditional systems project with some change management tasks. Such repositioning should result in increased identification and understanding of the 'people' and political issues at an earlier stage. This process would help define consequences of early decisions more clearly, and, hopefully, decrease the impact of people issues on project failure rates.

\subsection{Implications for research}

Continuing research associated with this model includes further analysis of the linkages between leadership decision-making, organisational learning and change leadership. Current additional research also includes analysis of quality in leadership decisionmaking and its relationship with change leadership. There is, we believe, a need for further research in project governance, particularly in the effectiveness of project sponsorship. The BGR model needs to be tested empirically to determine whether the relationships are consistent with the themes presented in this paper. The authors hope that other scholars might be interested in exploring the links in the model in subsequent research.

\section{References}

AAP (2010) 'State knew of Queensland health payroll system risk: two bureaucrats axed', Courier-Mail, 29 June.

A Guide to ERP Success (2001) Robbins-Gioia, LLC, Alexandria, VA.

Armenakis, A. and Bedeian, A. (1999) 'Organizational change: a review of theory and research in the 1990s', Journal of Management, Vol. 25, No. 3, pp.293-315.

Bakan, J. (2004) The Corporation: the Pathological Pursuit of Profit and Power, Free Press, New York. 
Benson, B. and Soldo, E. (2010) Lessons from Abroad: Leading Organisational Success through Sustainable Leadership, University of Pretoria, Pretoria, South Africa, 18-20 May.

Brown, M.E. and Trevino, L.K. (2005) 'Ethical leadership: a social learning perspective for construct development and testing', Organizational Behaviour and Human Decision Processes, Vol. 97, pp.117-134.

Buchanan, D.A. (2008) 'You stab my back, I'll stab yours: management experience and perceptions of organization political behaviour', British Journal of Management, Vol. 19, No. 1, pp.49-64.

Burke, W.W. (2002) Organization Change: Theory and Practice, Sage, Thousand Oaks, CA.

Burnes, B. (1996) Approaches to Change Management, Pitman Publishing, London.

Caldwell, A. (2010) 'Queensland health's Mr Fixit battles for answers over payroll shambles', Courier-Mail, 19 April.

Ciulla, J.B. (2006) 'Ethics: the heart of leadership', in Maak, T. and Pless, L. (Eds): Responsible Leadership, Routledge, NY.

Coldwell, D. (2010, May) Running Heading: Interfaces in Management Freedom, Moral Orientations and Corporate Instrumentality: Towards a Model of Responsible Management, University of Pretoria, Pretoria, South Africa.

Cooke, D., Gelman, L. and Peterson, W. (2001) ERP Trends, The Conference Board, Canada.

Dassah, M.O. (2010) Responsible Leaders: Attributes and Roles in a Multi-challenged Global Business Environment and Implications for Leadership Development, University of Pretoria, Pretoria, South Africa, 18-20 May.

Dunphy, D. and Stace, D. (1993) 'The strategic management of corporate change', Human Relations, Vol. 46, No. 8, pp.905-920.

Eser, B., Hage, B., McKenna, M. and Wilckzynski, H. (2007) Performance-Improvement Initiatives: Three Best Practices for Project Success, Booz Allen Hamilton, Inc., Atlanta.

Ferris, G.R., Adams, G., Kolodinsky, R.W., Hochwarter, W.A. and Ammeter, A.P. (2002) 'Perceptions of organizational politics: theory and research directions', in Yammarino, F.J. and Dansereau, F. (Eds): The Many Faces of Multi-level Issues (Research in Multilevel Issues, Vol. 1), Emerald Group Publishing Limited, pp.179-254.

Fulmer, R.M. (2005) 'What leaders and their organizations can do to develop ethical leaders', in Dobbs, S.M. and Stumpf, S.A. (Eds): Handbook on Responsible Leadership and Governance in Global Business, Edward Elger, Cheltenham, UK.

Green, S. (2009) Good Value: Reflections on Money, Morality and an Uncertain World, Penguin Books, London.

Keller, S. and Aiken, A. (2008) The Inconvenient Truth about Change Management. Why Change Programs Fail, McKinsey \& Co., New York.

Koestenbaum, P., Keys, P.J. and Weirich, T.R. (2004) 'Integrating sarbanes-oxley, leadership and ethics', The CPA Journal, Vol. 75, No. 4, pp.13-15.

Kotter, J. and Cohen, D.S. (2002) The Heart of Change: Real Life Stories of how People Change their Organisations, Harvard Business School Press, Boston, MA.

KPMG (1997) Canada Survey, KPMG, Toronto.

Latta, G. (2006) A Process Model of Organizational Change in Cultural Context (OC3 Model): The Impact of Organizational Culture on Leading Change, University of Nebraska, Lincoln, Nebraska.

Lynham, S.A., Taylor, R.G. and Naidoo, V. (2010) Responsible Leadership for Performance: The Description of a Theoretical Framework and its Application to a South Africa Case Study on Business Leadership, University of Pretoria, Pretoria, South Africa.

Miles, J. and Wardill, S. (2010) 'Experts fly in to fix Queensland health pay bungle', Courier-Mail, 15 April. 


\section{The BGR contingency model for leading change}

Neubert, M.J., Carlson, D.S., Kacmar, K.M., Roberts, J.A. and Chonko, L.B. (2009) 'The virtuous influence of ethical leadership behavior: evidence from the field', Journal of Business Ethics, Vol. 90, pp.157-170.

OASIG (1995) IT Failure Statsitcs, OASIG, London.

Patzer, M. and Voegtlin, C. (2010) Leadership Ethics and Organizational Change: Sketching the Field, University of Zurich, Zurich, Switzerland.

Petouhoff, N., Chandler, T. and Montag-Schmatz, B. (2011) The Business Impact of Change Management, Graziaidio Business Review, Pepperdine University, Los Angeles, CA

Phelan, M.W. (2005) 'Cultural revitalization movements in organization change management', Journal of Change Management, Vol. 5, No. 1, pp.47-56.

Qassim, A. (2010) Why Information Systems Projects Fail: Guidelines for Successful Projects, Information technology Department State Audit Institution, Oman.

Richoltz, B. (2009) Bailout Nation: How Greed and Easy Money Corrupted Wall Street and Shook the World Economy, John Wiley \& Sons, Inc., Hoboken, NJ.

Robertson, J. and Solomons, M. (2011) 'Insurer "laughs" at flood victim in email', The Courier Mail, 9 April.

Rosenthal, J. (2009) Leadership as Practical Ethics, Policy Innovations, Carnegie Council, Washington, DC.

Schwab, K., Zahidi, S., Rojas, M., Finnell, T., DeGioia, J. and Banchoff, T. (2010) Faith and the Global Agenda: Values for the Post-Crisis Economy, The World Economic Forum, Georgetown University, Geneva, Switzerland.

Sims, R.R. (2003) 'Ethical business missteps: the former and current state of affairs', Ethics and Corporate Social Responsibility: Why Giants Fall, Praeger, London

Smith, R. (2011) Aristotle's Logic, Stanford.

The Standish Group (1995) CHAOS, The Standish Group Report.

Velasquez, M., Moberg, D., Meyer, M.J., Shanks, T., McLean, M., DeCosse, D., Andre, C. and Hanson, K.O. (2009) A Framework for Ethical Thinking, Markkula Center for Applied Ethics, Santa Clara University, Santa Clara. 